\title{
Research on Hybrid Teaching in the Experimental Teaching of Principles of Computer Composition
}

\author{
Yi Qian* \\ Department of Information Science and Technology, Taishan University, Taian 271000, Shandong Province, China \\ *Corresponding author: Yi Qian, bjkdqy@126.com
}

\begin{abstract}
Aiming at the issue of professional engineering certification, this article introduces the hybrid teaching method to the teaching of Principles of Computer Composition, as the core course of computer specialty in applied undergraduate colleges, as well as discusses the experimental teaching method of this course. The teaching scheme is designed in the aspects of experimental teaching platform, teaching content, and student achievement assessment. By making full use of online and offline resources, this teaching method realizes the diversification of learning materials and learning means, the threedimensional learning space and learning time, as well as effectively improves the teaching effect and quality.
\end{abstract}

Keywords: Hybrid teaching; Experimental teaching; Principles of computer composition; Diversification

Publication date: December 2021; Online publication: December 27, 2021

\section{Introduction}

The certification requirements for engineering education clearly state that students must be able to design solutions to solve complex engineering problems in the computer field, independently design software and hardware systems, modules, or algorithm processes that meet specific needs, reflect the sense of innovation in the design process, as well as consider social, health, safety, legal, cultural, and environmental factors ${ }^{[1]}$. The teaching of Principles of Computer Composition mainly involves the learning of basic structure, working principle, analysis, and design of computer hardware ${ }^{[2]}$. Through this course, students would have a complete and clear understanding of the five components of a computer, understand the hardware structure, and develop certain skills in analyzing and designing hardware. Therefore, experimental teaching is particularly important in this course ${ }^{[3]}$.

In order for students to learn well in this course, many teachers have explored and put forward reform plans. Beginning from the actual work in an applied undergraduate university - Taishan University, this article summarizes and discusses the online and offline hybrid teaching method, in which the teaching effect has significantly improved with this method.

Hybrid teaching integrates online and offline teaching resources by using micro-courses recorded by teachers ${ }^{[4]}$. Therefore, learning is no longer limited to only a few hours in class but expanded in such a way that it can be done anytime and anywhere. The acquisition of extracurricular knowledge is no longer from just books or experimental boxes but a wealth of digital resources. This diversified and three-dimensional learning consolidates the status of students as the main body of education, giving full play to their subjective initiative and effectively improving their learning efficiency ${ }^{[5,6]}$.

In hybrid teaching, the integration of teaching resources, the control of students' learning progress, and the type of assessment methods should be paid attention to in the process of teaching reform ${ }^{[7]}$. Through this study, the problems existing in the current experimental teaching of Principles of Computer Composition have been analyzed, the experimental teaching of Principles of Computer Composition has 
been reformed according to the requirements of the engineering certification, a more reasonable experimental teaching scheme has been designed, the students' practical skills has improved, and a solid foundation for the study of subsequent related courses has been laid.

\section{Problems in the experimental teaching of Principles of Computer Composition}

For many years, Taishan University has been using the "Dais-CMX16 + principles of computer composition experimental box" developed by Wuxi Huawen Merck Instrument Co., Ltd. The experimental system consists of the experimental platform, switching power supply, and software. Most of the experiments it provides are confirmatory experiments. Students only need to operate the experimental box with reference to the experimental instructions during experiments; they can easily complete those experiments by directly inserting wires and controlling switches as well as buttons.

After years of teaching feedback, many students are still confused about what they have learned upon completion. As there are many confirmatory experiments and students lack reasoning, students' innovative skills cannot be cultivated. Just by observing the experimental results, they are not able to understand the internal working principle of the system. Many students can easily pass by copying the experimental instructions. It is irrational to determine their scores according to the experimental report after the experiment. Moreover, the experimental box is relatively fixed to the course content, which is not conducive to the penetration of software and hardware courses.

\section{Double combination in hybrid teaching}

Double combination refers to the combination of "online" and "offline," as well as the combination of theory and experiments. Experimental teaching can be carried out in several ways.

(1) The experimental process is the basis of knowledge accumulation and application.

Teachers would provide the experimental questions according to the teaching progress in theory. The students would then complete the questions based on their theoretical knowledge. After completing the component experiment step by step, students can cooperate with the theoretical final examination to complete the practice of model machine design. The design begins from clarifying the function of CPU, and subsequently, designing the instruction system, determining the overall structure, drawing state diagrams, forming control logic, as well as connecting various components. Finally, the design can be completed, and the model machine can be implemented. Students can then write specific programs according to the instruction system, store them in the main memory, run them in the model machine, and realize the program function. Depending on each student, interrupts and exception handling can also be added to the model machine. Such a complete experimental system in combination with theoretical teaching can help students further understand the component composition and working principles of computers as well as establish the concept of the whole machine. It is of great significance to cultivate students' systematic design skills.

(2) Experimental summary is the sublimation of the experimental process.

In fact, summaries provide students a space to reflect on their own design. Summaries are not only the combing of the design process, but also a further understanding of the experimental principle. At the same time, multi angle reflection can broaden students' thinking space and further stimulate their innovative thinking. According to different assessment methods, in the whole process from component practice to model machine practice, students can upload the documents for the design and summary to the system after each project has been completed or hand over the summaries to 
their teachers.

In double combination, experimental operations are added, and the acquisition of students' knowledge is more diversified and three-dimensional. This method effectively improves the teaching effect and further cultivates students' practical skills as well as creativity.

\section{Experimental teaching scheme of Principles of Computer Composition}

\subsection{Design of experimental teaching scheme}

Firstly, based on the actual situation in Taishan University and in consideration of the certification requirements, relevant experimental teaching contents have been designed.

Experiments can be divided into confirmatory experiments, design experiments, and comprehensive experiments.

Confirmatory experiments are carried out to consolidate the theoretical knowledge learned. The purpose of design experiments is to improve students' analysis and application skills as well as further deepen their understanding of what they have learned. Comprehensive experiments are carried out to cultivate students' comprehensive ability.

Now, according to the requirements of the engineering certification, new experimental equipment should be purchased, and the following four main experimental teaching schemes should be designed:

(1) Experiment 1 is the register experiment. Register is mainly used to save data.

Objective: To understand the structure, working principle, and data writing control method of various registers in the model machine.

Experiment content: The data is written into A and $\mathrm{W}$ registers. There are also data register groups, R0-R3, memory address register (MAR), stack register (ST), and output register (OUTR).

(2) Experiment 2 is the arithmetic unit experiment. The arithmetic unit mainly performs logic operations and arithmetic operations. The arithmetic unit is realized by an electronic programmable logic device (EPLD). There are 8 kinds of operations, which are determined by S0, S1, and S2, respectively.

Objective: To master the data transmission channel of arithmetic unit and understand the working principle of addition, subtraction, multiplication, and other operations under arithmetic logic operations.

Experiment content: The arithmetic logic unit (ALU) (74LS181) execution principle and method are verified, and some simple data operations are performed.

(3) Experiment 3 is the expanded memory (EM) experiment. Main memory plays an important role in computers. There are mainly two experiments: one of it is memory reading and writing, while the other is memory expansion.

Objective: To master the working characteristics and application methods of static memory RAM, as well as to understand the corresponding relationship between various control signals in static memory.

Experiment content: Set up different output addresses, write different data into MAR, and read the data.

(4) Experiment 4 is the experiment of microprogram controller. The microprogram controller mainly decodes micro instructions and sends out control signals. The timing signals during the execution of the microprogram are provided by the timing generator. 
Objective: To understand the composition principle of microprogram controller, the format of micro instruction, and the function setting of each field, as well as to master the use of assembly language to write microprograms, run programs, observe the operation of microprograms, and analyze the meaning of instructions.

Experiment content: Write assembly language program, input it into the controller and debug it. The program mainly includes data transmission, data operation, shift inversion, transfer experiment, call experiment, and understanding how PCs (personal computers) work.

\subsection{Improvement of experimental teaching method}

The improvement of the experimental teaching method of Principles of Computer Composition is mainly through two ways.

(1) Echelon-structured guidance.

It is easy for students to master the confirmatory experiment. However, for design and comprehensive experiments, instructors need to explain them in simple terms. There are more than 50 students in a class; therefore, it is difficult to guide each student individually within a limited time. In that case, the echelon-structured guidance is adopted. Taking the class of 50 as an example, according to the teaching feedback, five students are selected as teaching assistants. The teacher guides the five students in advance, and subsequently, the five students guide another ten students to preview the experiment during their spare time; following that, the ten students then guide twenty other students. Students should preview the experimental content before their lessons. During the preview, different design schemes and ideas should be put forward. These schemes and ideas can be discussed, and various tasks can be assigned in groups. In this way, there will be more time to complete the remaining verification work and look for the answers to the questions, thus improving the efficiency of the experimental class. Moreover, mutual guidance among students is conducive to the deepening of friendships.

(2) Network teaching platform.

The teaching team of Principles of Computer Composition has jointly built an experimental teaching platform. CAI (Computer Assisted Instruction) courseware and experimental animation videos should be uploaded on the network platform. Through the network message board, problems encountered by the students can be answered, and the students would be mobilized to learn efficiently using modern information technology.

\subsection{Examination standard of experimental teaching}

In order to further improve the experimental efficiency, students must be assessed. In hybrid teaching, according to the professional training plan, the score may be the total score, either the combination of theoretical score and experimental score, or the separation of theoretical score from the experimental score.

The results of experimental teaching can be in many ways. There are three different reference methods.

(1) "Offline" results by teachers. Teachers provide comprehensive experimental results according to the students' performance, design difficulty, defense, summary report, etc.

(2) "Offline" results by students. Each student provides feedback according to their own experimental summary. Other students would then listen and give scores. The score is the average of the scores given by other students. 
(3) Combination of "online" and "offline." According to the summary on the online system, students will give scores, obtain the average value, and excellent students would then respond.

The preview before the experiment is to encourage students to consult relevant literatures and have a preliminary idea of the experimental content. The examination is conducted to avoid students from carrying out the experiment by simply copying the experimental reports done by other students. The report after the experiment allows students to analyze and summarize the experimental results as well as assess the data analysis, code debugging, and result summary.

\section{Teaching reflection}

The premise of effective hybrid teaching is as follows:

(1) under hybrid teaching, in regard to the design and implementation of supporting "online" system for experimental teaching, the "online" system of experimental teaching should not only include teaching, test questions, and other resources, but also interactive platforms to meet the corresponding assessment methods;

(2) the school's recognition of "online" courses and the teachers' familiarity with "online" resources under their specialty are required to implement hybrid teaching; at the same time, the school has supporting resources.

Hybrid teaching combines the advantages of online teaching and offline teaching, in which students' learning efficiency can be improved. In particular, the hybrid teaching of double combination gives full play to students' subjective initiative to the greatest extent; the assessment method is more flexible, which fully improves the comprehensive strength of students. In order to effectively implement hybrid teaching, schools need to provide resources and policy support, while teachers need to spend more energy on organizational work.

\section{Conclusion}

According to the requirements of the engineering certification, the experimental teaching of Principles of Computer Composition has been designed. In the design process, the cultivation of students' skills is emphasized more. The experiment is designed through experimental equipment, experimental purpose, experimental requirements, experimental content, experimental teaching materials, experimental examination, and so on. According to the feedback of the final effect of the experiment, the scheme stimulates students' interest in learning while having a more specific understanding of the computer hardware system; in addition, some abstract concepts can be further understood through the experiment. On the other hand, it improves students' practical skills and allows them to have a comprehensive understanding of the computer system. However, there are still many problems to be solved in experimental teaching, such as experimental equipment, which requires further improvement.

\section{Funding}

This research was supported by the 2021 Ministry of Education Industry-University Cooperation Collaborative Education Project - Discussion on Online and Offline Hybrid Teaching of Customer Relationship Management” (Project Number: 202101101013).

\section{Disclosure statement}

The author declares that there is no conflict of interest. 


\section{References}

[1] Lan Y, Zhang C, 2019, Exploration and Practice of Teaching Reform of Computer Composition Principles. Computer Education, 289(1): 13-15.

[2] Yang J, 2018, Exploration on Teaching Reform of "Principles of Computer Composition" for Applied Undergraduates. Fujian Computer, 34(11): 169-170.

[3] Wang X, Qiu X, 2018, Research on the Reform of Teaching Mode of Computer Composition Principle. Computer Knowledge and Technology, 14(33): 144-145.

[4] Shao X, Ye Z, 2018, Discussion on the Teaching of Computer Composition Principle Based on System Ability Training. Computer Education, 2018(11): 27-30.

[5] Yang Y, Huang J, Wu Z, 2015, Implementation Scheme Design of Online and Offline Hybrid Teaching Mode. Curriculum Education Research, 2015(5): 3-4.

[6] System Administrator, 2020, Engineering Education Certification Standard (Revised in November 2017). China Engineering Education Professional Certification Association. https://www.ceeaa.org.cn/gcjyzyrzxh/rzcxjbz/gcjyrzbz/tybz/599711/index.html (accessed on December 1, 2021).

[7] Zhang L, Zheng R, Tian J, 2013, Experimental Teaching Reform of Principles of Computer Composition. Experimental Science and Technology, 2013(4): 107-110. 